\title{
Análise coletiva de acidentes de trabalho: dispositivo de intervenção e formação no trabalho
}

\author{
Camila Aloisio Alves ${ }^{\mathrm{I}, 1}$ e Claudia Osorio ${ }^{\mathrm{I}, 2}$ \\ IUniversidade Federal do Rio de Janeiro \\ ${ }^{\mathrm{II}}$ Universidade Federal Fluminense
}

\begin{abstract}
O artigo apresenta a Análise Coletiva de Acidente de Trabalho, desenvolvida pela Comissão de Saúde do Trabalhador do Hospital dos Servidores do Estado, como um dispositivo de atuação junto aos profissionais que aí se acidentam. Trata-se de uma ferramenta de intervenção norteada pela metodologia da corrente francesa da psicologia do trabalho denominada Clínica da Atividade. A discussão do método de análise é ilustrada com a descrição de um caso, relativo a um acidente ocorrido com uma profissional de enfermagem. Observa-se, neste caso, deslocamentos e ampliações produzidos na concepção que a profissional tem da sua atividade, que passa a abranger a discussão crítica do gesto técnico, das formas de transmissão destas técnicas e do caráter coletivo da atividade.
\end{abstract}

Palavras-chave: Saúde do trabalhador, Acidentes de trabalho, Atividade.

Collective analysis of occupational accidents: a device to intervention and training in work

The paper discusses a method of Collective Analysis of Occupational Accidents developed by the Occupational Health Commission of the Hospital dos Servidores do Estado, a device based on the French occupational psychology current named Activity Clinic. The discussion is illustrated by a case description, the case of an accident with a professional of the nursery group. It shows the changes and enlargements produced in the professional's conception of her activity, including in it the critics of the technical acts, its transmission forms and the activity collective aspects.

Keywords: Occupational health, Occupational accidents, Activity.

$\mathrm{O}$ presente artigo apresenta o método que norteia a prática desenvolvida na Comissão de Saúde do Trabalhador do Hospital dos Servidores do Estado (CST/HSE), hospital público situado na cidade do Rio de Janeiro, no que concerne à análise dos acidentes com pérfuro-cortantes que aí ocorrem.

A Análise Coletiva de Acidentes de Trabalho (ACAT) é fruto de uma prática que se inicia em 1996 com um convênio entre o Hospital dos Servidores do Estado e a Universidade Federal Fluminense, com o objetivo de abrir campo de estágio a alunos de graduação em Psicologia, na área de Saúde do Trabalhador. Nesse artigo será apresentado o método elaborado, bem como as bases teóricas que o sustentam, ilustrando essa apresentação com um caso real de acidente analisado em meados do ano de 2002. A apresentação a partir de um estudo de caso nos permitirá indicar as características do método e discutir algumas de suas possibilidades e limites.

A psicologia do trabalho, bem como a ergonomia, tem proposto diversos métodos de análise do trabalho e dos acidentes. De um modo geral, parte-se de um modelo epistemológico que é o da precedência do saber científico sobre o saber prático - o analista é um expert - e da precedência do conhecimento teórico sobre a aplicação desse conhecimento. Assim, a redução dos acidentes estaria condicionada à realização de projetos pedagógicos em que o conhecimento necessário é passado daquele que sabe àquele que não sabe.

1 Residente de Saúde Coletiva, Universidade Federal do Rio de Janeiro.

2 Docente do Departamento de Psicologia da Universidade Federal Fluminense. 
Nesta proposição, o método de análise de acidentes parte de um outro pressuposto: o de que são as intercessões ${ }^{3}$ entre o conhecimento científico e aquele advindo da experiência que produzem a vitalidade de um ofício e sua possibilidade de reduzir os constrangimentos e riscos que possam existir no curso das atividades de trabalho. A experiência por sua vez remete à história daquele ofício, de uma dada organização, de um determinado grupo de trabalho e do sujeito envolvido no acidente. Neste sentido, a análise proposta é participativa e coletiva, tanto por reunir concretamente participantes diversos, que ocupam diferentes funções, como por supor que o saber e a experiência não são nunca individualmente produzidos.

Tendo sido proposto publicamente em data recente (Osorio da Silva, 2002), parecenos que a discussão deste método pode trazer contribuições às práticas em psicologia do trabalho e saúde do trabalhador.

\section{A saúde do trabalhador e a análise de acidentes no Hospital dos Servidores do Estado}

A CST/HSE vem pautando suas ações na concepção de Saúde do Trabalhador como parte integrante do campo da saúde pública, mantendo claro compromisso de transformação das condições de trabalho, e a valorização da participação do trabalhador como constitutiva das metodologias adotadas (Machado, 1997; Minayo-Gomez \& Thedim-Costa, 1997). Seu programa de prevenção e controle dos acidentes com pérfuro-cortantes e exposição a fluidos biológicos foi iniciado no segundo semestre de 1996, após um seminário de Saúde do Trabalhador que indicava tais ações como prioritárias. Foram desenvolvidas ações de educação em saúde, informando sobre as medidas e formas de agir consideradas adequadas na área de biossegurança ${ }^{4}$; paralelamente, procedeu-se à implantação, no HSE, de caixas rígidas coletoras de pérfuro-cortantes, seguindo as prescrições aprovadas internacionalmente (Center for Disease Control, 1989). Implantou-se também o atendimento médico aos acidentados, realizado pela Divisão de Doenças Infecto-Parasitárias (DIP/HSE), a qualquer hora do dia ou da noite, sendo avaliado o grau de risco de contaminação e indicadas as medidas profiláticas pertinentes. Estes acidentes são incluídos em registro estatístico do HSE e notificados à Secretaria Municipal de Saúde e à Divisão Municipal de AIDS.

A partir de 1998, já havendo uma rotina de análises quantitativas dos acidentes com pérfuro-cortantes e exposição a fluidos biológicos, decidiu-se pela implantação de análises qualitativas destes acidentes. Tendo observado que a informação por si mesma é insuficiente para produzir modos de fazer mais seguros, a CST buscava um modo de atuar que produzisse a construção coletiva de conhecimentos sobre o trabalho, em especial, sobre os processos de trabalho em ambiente hospitalar.

Passou-se a entrevistar os funcionários acidentados, a fim de compreender e registrar sua percepção das situações propiciadoras do acidente e das medidas que poderiam ser tomadas para reduzir a probabilidade de ocorrência de eventos semelhantes; visava-se também acolher possíveis demandas de suporte psicológico neste momento. Os estudos realizados a partir dos dados registrados (Chaves et al., 1999), a experiência de trabalho com

3 De acordo com Passos e Benevides de Barros (2000), devemos diferenciar as noções de interseção e intercessão. No primeiro caso, trata-se de uma interdisciplinaridade: a relação é de conjugação de dois domínios na constituição de um terceiro, que se espera estável, idêntico a si e para o qual pode-se definir um objeto próprio. No segundo, que é o caso da transdisciplinaridade, a relação que se estabelece entre os termos que se intercedem é de interferência, de intervenção através do atravessamento desestabilizador de um domínio qualquer sobre outro.

4 De 1996 a 2002 foram realizados treinamentos formais e em serviço, atingindo o pessoal de enfermagem, o pessoal médico (especialmente residentes) e o pessoal de limpeza. Este último grupo é contratado por uma empresa terceirizada e tem alta rotatividade, sendo necessária supervisão constante. 
essa abordagem qualitativa e o encontro com novas abordagens teóricas levou à proposição, em 2002, de um método da Análise Coletiva dos Acidentes de Trabalho - ACAT (Osorio da Silva).

\section{O método da Análise Coletiva dos Acidentes de Trabalho}

O dispositivo de análise proposto vem sendo produzido na interceção da corrente francesa da Psicologia do trabalho denominada Clínica da Atividade (Clot, 1999) com outras referências que já são familiares aos que atuam na Vigilância em Saúde do Trabalhador no Brasil (Minayo-Gomez \& Thedim-Costa, 1997).

A Clínica da Atividade nos apresenta uma interessante discussão da função psicológica do trabalho, abordando-o sob o ponto de vista do real da atividade, ou seja, implica analisar não apenas o trabalho prescrito, aquele efetivamente realizado, mas também o caminho de conflitos e decisões que se interpõe entre a prescrição e o que ocorre na realidade do trabalho.

Segundo Yves Clot (1999a), principal autor desta corrente, a atividade não é somente aquilo que se faz. $\mathrm{O}$ real da atividade é também aquilo que não se faz, que não se pode fazer, que se tenta fazer sem lograr êxito - os fracassos - o que se poderia ter feito ou desejado fazer, o que se pensa poder fazer em outros lugares. $\mathrm{O}$ real da atividade transborda o gesto realizado e sua análise permite o acesso às motivações, preocupações e desejos, empecilhos e dificuldades que permeiam o trabalho. De acordo com Clot, o debate sobre tais aspectos do trabalho permite transformá-lo, tornando-o um meio para ampliar e recriar a experiência.

Para orientar-se no caminho entre o trabalho prescrito e o trabalho realizado, o trabalhador refere-se a recursos fornecidos pelo que a Clínica da Atividade denomina o gênero profissional. $O$ gênero de cada ofício retém, nesta concepção, a memória impessoal de um meio de trabalho, através de suas expressões características, suas dicas e regras explícitas e implícitas, conservando e transmitindo sua história. Sendo assim, o gênero profissional é o mesmo tempo um recurso técnico e psicológico. O gênero torna habilitado. Ele pode também tornar desastrado, se está desajustado e perde sua eficácia; surgem então mal entendidos e insucessos na ação. $\mathrm{O}$ gênero possui uma capacidade normativa, conserva uma função psicológica para cada trabalhador, fornecendo recursos aos sujeitos para agir, se defender ou tirar o melhor proveito da situação de trabalho. Se esses recursos se esgotam, a vida psicológica no trabalho se vê gravemente diminuída (Clot, 1999b).

No método proposto, a tarefa consiste em estabelecer um diálogo que propiciará aos trabalhadores deslocar-se para a posição de observador de seu próprio trabalho, suscitando o desenvolvimento dos recursos subjetivos e objetivos disponíveis para sua permanente recriação. Visando a elucidação das questões envolvidas no curso dos acontecimentos que propiciaram o acidente, estabelece-se um diálogo entre o trabalhador e o analista do trabalho, neste caso, estagiárias de psicologia atuantes na CST/ $\mathrm{HSE}^{5}$, que se desenrola no ambiente em que o acidente ocorreu; neste, objetiva-se que o trabalhador possa não só relatar como também encenar a seqüência de acontecimentos envolvidos na situação. É um diálogo que não tem um roteiro definido, mas um eixo norteador, podendo abarcar um conjunto amplo das questões envolvidas no acidente e que dizem respeito tanto ao trabalho prescrito, quanto ao trabalho realizado.

5 Desenvolve-se, na CST, um estágio em Saúde do Trabalhador, para alunos de graduação, em convênio com a Universidade Federal Fluminense e sob a supervisão de uma das autoras desse artigo, Claudia Osório. 
Importante ressaltar que, durante a entrevista, preconiza-se o uso do como e não do por que, uma vez que, utilizando o primeiro, abrimos ao trabalhador a possibilidade de construção de um relato e não de sucessivas justificativas, que tenderiam a fazê-lo se sentir culpado pelo acidente e assim se colocar numa posição defensiva frente à intervenção do processo analítico ${ }^{6}$.

O momento da encenação da seqüência dos acontecimentos imediatamente anteriores ao acidente desloca o trabalhador para a posição de observador seus próprios atos, desconstruindo o automatismo alcançado ao longo dos anos de profissão e colocando-o em condições de recriar os gestos contidos em sua prática. Esta recriação poderá ter como efeito propiciar o desenvolvimento do que Yves Clot denomina o gênero profissional, com referência a uma construção coletiva de seu ofício.

Constrói-se, após a encenação, um diagrama em que os fatos antecedentes são registrados, postos numa folha de papel, na qual desenha-se uma rede que entrecruza os eventos e tarefas descritos até então. Esta etapa é feita com a participação ativa do trabalhador que, o tempo todo, indica ao analista a melhor forma de elaboração do diagrama. Ao final da entrevista, é indagado ao trabalhador quais sugestões e/ou propostas ele teria, e que poderiam ser implementadas, para que a freqüência dos acidentes diminuísse ou que o risco fosse reduzido.

A atenção do analista deve sempre estar voltada para o entendimento do ambiente e da dinâmica de trabalho do profissional em questão, pois o foco está na vivência do acidentado acerca do seu acidente. O diálogo com o analista funciona como dispositivo de análise e intervenção, uma vez que este pontua e questiona, pretendendo criar um movimento reflexivo naquele que está sendo entrevistado. $\mathrm{O}$ analista e o trabalhador copiam o esboço construído, que deverá ser utilizado como suporte para refletir e re-elaborar o que se relatou, encenou e registrou.

Essas reflexões e re-elaborações são recolhidas e desenvolvidas num novo encontro, definido como a terceira etapa da análise. Estabelece-se uma discussão entre acidentado e analista sobre o que foi percebido, apreendido e elaborado durante esse processo, desde o momento em que o analista intervém no ambiente de trabalho do profissional, tirando-o das suas atividades rotineiras e buscando estabelecer um repensar em relação ao seu próprio trabalho, até a concretização do diagrama como instrumento que registra os traços do processo que envolveu o acidente.

Para finalizar, são focalizadas e organizadas as sugestões e ações que podem ser iniciadas para alcançar alguma melhoria efetiva das condições de trabalho no setor de trabalho posto em análise.

Busca-se, com esse método, proporcionar, ao trabalhador que se acidenta, a oportunidade de ocupar o lugar de observador de si mesmo, estimulando sua ativa participação na manutenção e recriação dos recursos objetivos e subjetivos de que dispõe para a realização adequada de suas tarefas. Na medida em que o analista se coloca na posição de apoio ao profissional, para que ele se desloque e se auto-observe, abre-se a possibilidade para que os conteúdos cognitivos envolvidos na prática do trabalho sejam repensados e recriados, dando origem a novos modos de operar o dia-a-dia do trabalho. $\mathrm{O}$ dispositivo pretende propiciar o conhecimento do trabalho hospitalar para e pelos próprios profissionais de saúde, favorecendo o desenvolvimento do seu gênero profissional e a efetiva realização das transformações que porventura estes considerem pertinentes.

Nesse sentido, trabalha-se com aspectos de ordem coletiva que conformam o gênero profissional, acima mencionado, como os ensinamentos presentes na formação dos

6 A intervenção na ocorrência de acidentes de trabalho pela via de culpabilização do acidentado, a vítima, tem sua referência nas teorias que analisam o acidente como resultado de um ato inseguro. Essa via deve ser ativamente recusada pelos que pensam o trabalho como processo histórico e a atividade em seu caráter coletivo. 
profissionais e por isso, acessíveis a todos que exercem esta profissão, como a sua história, seus paradigmas, suas orientações práticas e teóricas; ou como as soluções, formais ou informais, encontradas e legitimadas em cada equipe de trabalho; e com aspectos singulares de cada acidente ou mesmo da história de cada indivíduo. Esses âmbitos se atravessam e constroem um determinado fazer profissional que expressa a mistura do que se aprendeu e do que se é, erigindo algo em que o trabalhador e seus pares se identificam como pertencentes a determinada categoria profissional,

A análise é também coletiva por reunir especialista e trabalhador numa função não hierarquizada. A partir dessa interação entre analista e acidentado, em que um certo modo de subjetivação é posto a operar, se constrói, durante a análise, "um lugar onde se produziria aprendendo e, também, ao mesmo tempo, se reconstruiria a própria subjetividade" (CAMPOS apud OSORIO DA SILVA, 2002).

\section{Análise de um acidente: a aquisição de novos modos de operar}

Será relatado a seguir o diálogo desenvolvido com uma funcionária acidentada, em junho de 2002, durante a análise do acidente que esta havia sofrido. Esse relato irá ilustrar a discussão do método e de alguns de seus efeitos, observados no caso em foco.

A análise deste acidente inicia-se no momento em que o DIP/HSE foi visitado, pela CST, no intuito de fazer a busca ativa dos acidentes ocorridos naquela semana. A partir desse levantamento toma-se contato com algumas informações que guiam o entrevistador durante toda a entrevista com a profissional.

Consultando os atendimentos aos profissionais acidentados, a equipe da CST preenche, para cada acidente, uma Comunicação Interna de Acidente de Trabalho (CIAT) ${ }^{7}$. Num dos acidentes notificados, os dados registrados informavam que a profissional, uma auxiliar de enfermagem, havia se acidentado ao realizar um hemoglucoteste ${ }^{8}$, utilizando uma agulha oca de injeção, tendo esta perfurado sua mão direita. Segundo essas informações, a profissional alega que se acidentou por não ter reencapado a agulha logo após o seu uso. Observou-se, com estranheza, que a profissional seguira a regra - não reencapar ${ }^{9}$ - mas declarara que, ao escolher seguir o modo prescrito, cometera um equívoco. Ora, porque fazer justamente o oficialmente recomendado teria sido um erro?

A profissional foi procurada para a análise do acidente e os diálogos desenvolvidos serão transcritos a seguir.

Na primeira entrevista (Etapa 1), foi perguntado à profissional como havia sido o acidente, obtendo-se o relato que se segue.

AE - Estava indo para o leito do paciente, porque eu tinha que fazer um hemoglucoteste. Fui carregando nas mãos um chumaço de algodão, o aparelho, agulha e a fita para a medição. Depois que terminei todo o procedimento, fui recolher o material deixado na mesa de cabeceira junto do leito e, ao juntar tudo nas mãos, senti a agulha me furar.

7 A CST criou um instrumento de registro similar à CAT, uma vez que os trabalhadores atendidos são, em sua maioria servidores públicos federais e o processo de registro de seu acidentes de trabalho de servidores não se encontra ainda claramente regulamentado; a CIAT é encaminhada por processo administrativo ao Ministério da Saúde, passando a constar da folha funcional do servidor.

8 O hemoglucoteste serve para aferir o grau de glicose no sangue e o procedimento consiste em fazer um pequeno furo em algum dos dedos do paciente. Deste furo são extraídas algumas gotas de sangue, que são absorvidas pela fita medidora e assim, analisadas pelo aparelho que dará o resultado.

9 O reencape de materiais pérfuro-cortantes configura, de acordo com as regras de segurança atualmente vigentes (Center for Disease Control, 1985) uma atitude inadequada e perigosa. 
CST - Como que a agulha lhe furou?

$\mathrm{AE}$ - Furou no momento em que fui pegar todo material que estava em cima da mesa de cabeceira, como a agulha estava desencapada, ela me furou. Deixei desencapada porque estou fazendo um curso de atualização e o tema que estou estudando no momento é biossegurança e está sendo enfatizado o perigo de reencapar materiais pérfuro-cortantes. Mas se eu tivesse reencapado, nada disso tinha acontecido.

CST - Como assim, se você tivesse reencapado, você não ia se furar?

$\mathrm{AE}-E$ É que sempre reencapei agulhas para não me furar e não furar outros profissionais e nunca tive nenhum problema com isso; inclusive, sempre tive o maior cuidado na hora de reencapar, segurava prestando atenção e, quando ficava um pouco nervosa, encostava a capinha da agulha na parede, para servir de apoio na hora de encaixar. Mas, depois que fui alertada no curso, tentei reaprender e aplicar no dia-a-dia. Pelo visto, não deu certo.

CST - Você pode contar um pouco mais sobre as seqüências dos seus atos até o momento do acidente?

$\mathrm{AE}$ - Bem, como eu disse, peguei os materiais para fazer o hemoglucoteste no paciente

CST - Você utilizou bandeja, ou cuba rim, para transportar esse material?

$\mathrm{AE}$ - Não, não tinha cuba rim e eu não quis usar a bandeja, pois ia fazer um único teste; achei mais prático carregar tudo nas mãos. Chegando no leito do paciente, abri o invólucro da agulha, furei o dedo do paciente, coloquei a agulha na mesa de cabeceira, colhi a gota de sangue, que passei na fita medidora e o aparelho fez a leitura. Quando fui juntar todo o material para ir embora, peguei tudo de uma vez só com a mão, sem perceber que a agulha que eu havia utilizado estava no meio, foi aí que me acidentei. Por isso que eu disse que se tivesse reencapado a agulha nada disso teria acontecido, pois ela não teria me furado.

CST - Mas você havia dito que sabe que isso é errado, porque você aprendeu no seu curso, tanto que tentou corrigir seus atos.

$\mathrm{AE}-E$ É sei que é errado, acho que reencapar não é o ideal, mas convenhamos que se eu tivesse reencapado eu não teria me furado. Mas acho que vou tentar não fazer mais isso, é pela minha segurança.

CST - O que você fez depois que se acidentou?

$\mathrm{AE}$ - Logo após o acidente procurei o prontuário do paciente para conhecer seu histórico de saúde e constatei que não havia nada que indicasse uma probalidade de que ele fosse soropositivo. Despreocupei e não procurei de imediato o DIP. Fui lá só no dia seguinte, quando a minha consciência pesou, após ser alertada no meu curso que a procura é imprescindivel. Chegando lá, tomei uma bronca por não ter procurado no mesmo dia, colhi o sangue e tomei a medicação necessária.

CST - No dia do acidente você estava cansada ou estressada? A equipe estava completa? Você havia dobrado o plantão?

$\mathrm{AE}$ - Não, não estava cansada e no dia anterior não trabalhei em nenhum outro lugar. A equipe é pequena, mas estava completa nesse dia.

CST - E hoje, depois de tudo isso que você passou, alguma coisa modificou no seu dia-a-dia?

$\mathrm{AE}-$ Me sinto mais alerta para os perigos de qualquer acidente aqui no setor.

Ao longo desse primeiro contato algumas observações foram feitas quanto à organização do trabalho e a forma como a profissional lidou com as variáveis presentes no seu dia-a-dia. Interessa-nos analisar o caminho feito do trabalho prescrito, das normas aprendidas nos cursos e definidas nos protocolos, ao trabalho efetivamente realizado. Que escolhas foram 
feitas? Quais os conflitos vividos pelo trabalhador que, ao fazer de uma forma, está necessariamente deixando de seguir inúmeras outras possibilidades?

Inicialmente, cabe ressaltar que, quando a profissional não utilizou a bandeja e nem cuba rim para o transporte dos materiais, ela descumpriu uma norma de segurança. De modo geral considera-se que esta norma reduz tanto o risco de contaminações quanto o da ocorrência de acidentes, já que diminuiria o contato direto com o material pérfuro-cortante. A atitude de não preparar a bandeja é o resultado de uma alteração das regras, do trabalho prescrito, em prol da rapidez, visando economizar o tempo dispensado à tarefa.

Uma outra forma prescrita de reduzir riscos seria manter uma caixa de descarte nos locais em que os procedimentos de risco são realizados. No caso deste e outros serviços do Hospital em questão, a ausência de caixas de descarte junto aos leitos é consequência de uma escolha, considerando-se que há o risco do paciente manipular o conteúdo destas caixas.

$\mathrm{Na}$ entrevista, a profissional sugeriu, como solução, a compra de caixas coletoras de material pérfuro-cortante pequenas, que pudessem ser transportadas em uma bandeja para o leito dos pacientes, para que o descarte fosse feito com facilidade e eficiência. Nesse momento não foi discutida a dificuldade que tal solução acarretaria: a volta à cena da necessidade de preparar uma bandeja com os materiais e serem utilizados.

Em outro setor do hospital, já haviam ocorrido repetidos acidentes no decorrer desse mesmo procedimento técnico. A principal dificuldade mencionada pelos acidentados, nas entrevistas de análise desses acidentes, havia sido exatamente a ausência de caixas de descarte pequenas, em que as agulhas utilizadas poderiam ser depositadas imediatamente após o uso. Nesse outro setor surgiu como solução a compra, pela própria enfermeira, de pequenos potes de plásticos para o descarte provisório de agulhas e bisturis. Menores que as caixas de descarte disponíveis, esses potes poderiam ser transportados numa bandeja ou mesmo numa cuba.

A nova sugestão veio então reforçar a avaliação já feita anteriormente quanto à conveniência da compra, pela administração do hospital, de caixas pequenas o suficiente para caberem numa bandeja, o que foi encaminhado pela CST e aceito pelo hospital. ${ }^{10}$

Outro ponto importante a destacar refere-se à despreocupação inicial da profissional, que não procurou imediatamente o DIP. Novamente constatou-se um comportamento que contraria as regras estabelecidas. A profissional deveria ter procurado o quanto antes o setor pertinente, para que pudessem ser tomadas as devidas medidas, de imunização e profilaxia, reduzindo os riscos de Aids e de hepatite B e C. A profissional relata que, após ter ido ao curso e lá ser lembrada da importância das medidas profiláticas, "sua consciência pesou". Mesmo que se observe o uso de uma linguagem do senso comum, referindo mudanças de atitude motivadas pela culpa, não se pode negar a mobilização obtida. A ida ao DIP pode ser vista como uma reação à interferência de um interlocutor bem definido e que aparece no discurso pela segunda vez: o curso, seu(s) professor(es), conteúdos e debates. Antes, durante a primeira etapa da análise do acidente, já havia sido comentada a abordagem, no mesmo curso, das regras quando ao reencape/descarte de materiais. $O$ curso de atualização, as informações aí recebidas e os diálogos aí provocados produziram movimentos interessantes, de ampliação das considerações da profissional acerca de sua atividade de trabalho.

A atividade de trabalho é sempre dirigida, seja ao objeto de trabalho, seja aos pares ou hierarquias, seja ao próprio trabalhador: é uma atividade dialógica (Clot, 1999). Nesse caso, o diálogo com os professores produziu um desenvolvimento do modo de operar o dia-a-dia de trabalho, de proceder tendo em vista o evento "acidente".

10 É interesante observar que não foi mencionada até hoje, pelos trabalhadores acidentados, a possibilidade da compra de lancetas, já existentes no mercado, que retraem a ponta perfurante após o uso, evitando assim os acidentes. 
Nessa primeira entrevista não havia sido solicitado à profissional que mostrasse efetivamente como o acidente havia se dado, ficando o relato com vários pontos obscuros Passando para a segunda entrevista (Etapa 2), foi pedido à profissional que encenasse a situação em que o acidente ocorreu, mostrando os materiais usados e como ela os manuseava. Ela, então, pegou os materiais e levou os entrevistadores ao box da enfermaria; junto a um leito vago, e ali descreveu o que ocorrera naquele dia, refazendo cada gesto.

$\mathrm{Na}$ proposta original, ou seja, considerando o trabalho prescrito para a análise do acidente, esta encenação deveria ter ocorrido já no primeiro contato. No entanto, a atividade dos psicólogos do trabalho é como todas as demais, sempre inacabada. Como já foi dito, a solicitação de que a ação seja demonstrada motoramente, encenada, visa principalmente levar o profissional a posição de observador e analista do seu próprio trabalho. Aqui observase então uma outra justificativa para este modo de analisar o acidente: a possibilidade de uma compreensão mais clara por parte de todos os participantes do coletivo de análise, de como o acidente ocorreu.

Ao final desta segunda entrevista, perguntamos à profissional se algo havia mudado, depois do acidente, em seu modo de fazer e pensar, e ela relatou o que se segue:

\begin{abstract}
$\mathrm{AE}$ - Hoje me sinto mais alerta e, em diversos momentos, uso do meu próprio exemplo para que outros colegas de profissão não cometam os mesmos erros que eu. E acho muito importante que passe a ter, nos cursos de atualização, uma maior discussão sobre o hábito adquirido ao longo dos anos de profissão. Não basta só eles dizerem que está errado reencapar agulhas, eles também devem falar sobre a dificuldade em aplicar essa nova aprendizagem no dia-a-dia do trabalho. Desfazer esse hábito leva um tempo e não basta só dizer o que é certo ou errado, deve-se mostrar que a atenção no início ainda não está totalmente voltada para o novo conteúdo aprendido.
\end{abstract}

Observa-se que as intervenções da CST vieram alimentar um diálogo, ou debate, já iniciado com a interferência produzida pela participação da profissional no curso mencionado; deu-se um movimento, uma transformação, levando à profissional a um momento de reflexão e crítica acerca dos perigos de sua profissão, dos melhores modos de fazer a formação técnica e da sua possibilidade de ter ativa participação nesta, podendo vir a auxiliar outros colegas. Percebe-se o quanto é importante o trabalho de construção de novos modos de agir no momento em que os profissionais precisam estar alertas para a importância, ou os perigos, de pequenas atitudes e tomadas de decisões. Amplia-se assim o sentido que a profissional atribui ao seu próprio trabalho: ela passa a considerar a formação como uma troca, em que os professores devem ensinar aos alunos, mas também aprender com a experiência destes.

O momento de parada no cotidiano de trabalho produzido pela ACAT proporcionou à profissional a possibilidade de observar os procedimentos realizados, com suas inovações tecnológicas, tornando-a capaz de produzir, no grupo de trabalho, novos modos de observar e executar as tarefas que já haviam se cristalizado em gestos rotineiros. A profissional em questão apresentou, a partir da análise do acidente, o gesto profissional como um ato coletivo, a ser desenvolvido no conjunto da equipe de trabalho e na relação entre companheiros de ofício. E, mais uma vez, amplia o sentido atribuído a sua própria atividade quando se coloca na posição de comentar com as colegas sua experiência cooperando na construção de novos hábitos.

O lugar de observador do próprio trabalho, produzido pelo exercício de relatá-lo para um interlocutor externo à equipe, produz certos movimentos, o ângulo de observação muda, ampliando as escolhas possíveis nos modos de agir. Ao contar e recriar os fatos o trabalhador passa a ser seu próprio observador e com isso, a análise alcança seu objetivo principal, que é o de servir como ferramenta de formação e desenvolvimento no trabalho. 
Cria-se um dispositivo de intervenção capaz de provocar rupturas em condutas construídas ao longo dos anos de profissão, relacionadas ao aprendizado anterior, ou ao compromisso com o enfermo sobrepondo-se ao cuidado com sua própria saúde ${ }^{11}$. Dessa forma, pode-se atuar na construção de novos conteúdos cognitivos, contribuindo para que esse cuidado com o próximo seja ampliado para um cuidado do trabalhador consigo mesmo.

É possível observar o quanto o profissional, ao repensar a sua prática, através da análise do acidente, tem não só a oportunidade de analisar sua forma de trabalhar, como também de perceber que no seu trabalho diário, as regras/prescrições estão, a todo momento, interagindo com as possibilidades reais de concretização.

No caso dos funcionários do Hospital dos Servidores do Estado, encontram-se relações dos trabalhadores com a hierarquia naturalizada entre as categorias profissionais, sendo o médico, e não o enfermeiro, aquele que ocupa o topo da pirâmide e que detém a hegemonia nas decisões e discussões; relações com a estrutura política do sistema de saúde e do hospital, com a dificuldade de investimento financeiro; com os pacientes pertencentes a grupos de baixo poder aquisitivo e que chegam com quadros agravados por suas dificuldades em manter tratamentos prescritos e dietas adequadas; e relações que permeiam a vida do trabalhador, seja em casa, em cursos, com amigos etc. Nesse universo de intercessões e variabilidades, a distância entre trabalho prescrito e o trabalho real acentua-se, ou seja, a maneira como o trabalhado deve ser executado, o manuseio prescrito dos materiais e ferramentas necessários e o tempo previsto para cada tarefa não estão de acordo com as reais possibilidades de execução do trabalho.

A distância entre trabalho prescrito e real pode ser disparadora de saídas criativas que os trabalhadores encontram para organizarem e lidarem melhor com o processo de trabalho, como no caso, relatado anteriormente, da enfermeira que comprou potes pequenos que serviram de recipientes provisórios para o descarte de materiais pérfuro-cortantes e que foram alocados nas bandejas e cubas. Com isso, promoveu-se o desenvolvimento da atividade, enriquecida com a percepção da prevenção dos acidentes como tarefa coletiva. Mas, se o caminho da produção de saídas criativas encontra obstáculos, as cargas, ou sobrecargas, presentes nesse cenário podem trazer prejuízos, não só para a execução adequada da atividade, como, também, para a saúde do trabalhador que a executa. No caso em análise, a profissional procura um caminho que permita solucionar as novas questões produzidas pela entrada dois novos interlocutores: o curso de formação e a CST. Ao se colocar na posição de alguém que pode influenciar a formação dos colegas e faz a avaliação crítica do curso recebido, a profissional pode ter encontrado esse caminho.

\section{Análise coletiva de acidentes e formação permanente}

Nesta parceria estabelecida entre trabalhador e analista, a análise coletiva de acidentes serve como ferramenta capaz de desencadear transformações, tanto no modo de operar as tarefas diárias, como no modo prescrito, no instrumental disponível e outros aspectos técnicos relacionados a prevenção ou controle das variáveis envolvidas nos acidentes.

Cada acidente analisado carrega consigo um singularidade, pois envolve fatores e questões que variam de profissional para profissional, de ambiente para ambiente, de plantão para plantão etc. Por isso, os desdobramentos possíveis de uma análise de acidentes variam de caso para caso, pois dependem destas questões envolvidas com o mesmo.

11 Tais fatores são as explicações mais freqüentes para justificar o reencape das agulhas. 
A análise é, em si mesma, um dispositivo de intervenção que aciona um processo ímpar no dia-a-dia do trabalhador. Ao contar e recriar os fatos, o trabalhador não só se torna seu próprio observador como também amplia sua relação com seu ambiente de trabalho, construindo um novo olhar sobre os fatores que interferem e auxiliam a sua prática.

A análise do acidente relatado confirma o que já foi visto em pesquisas anteriores (Chaves et al., 1999): embora os trabalhadores, na sua maioria, conheçam as normas de segurança para o trabalho em hospital, este conhecimento não é suficiente para garantir seu cumprimento. No caso em foco, a profissional cita o hábito, construído e cristalizado ao longo dos anos de formação e prática, como o fator que interfere na apreensão de novos conteúdos. Embora ela não tenha reencapado a agulha, como era seu costume, essa nova aprendizagem ainda não tinha se sedimentado e, por isso, ela não estava atenta para a agulha desencapada.

As dificuldades observadas na adoção das normas de segurança, preconizadas pelo Center for Disease Control desde 1985, nos indicam que o hábito aprendido antes das novas normas ainda encontrava-se cristalizado e os gestos referentes ao mesmo permaneciam inseridos no fazer dessa profissional. Existem sempre diferenças entre o trabalho prescrito, supostamente correto e a atividade realizada, o gesto construído ao longo dos anos de profissão. Nesse caso, descreve-se a automatização diária, que ajuda economizando o planejamento dos atos futuros, com o que é prescrito: a não utilização da bandeja para carregar os materiais utilizados durante o procedimento, por se tratar de um único teste, caracteriza uma economia de atos em prol de uma eficiência e rapidez no pronto atendimento. Observa-se que a auxiliar de enfermagem está atravessada por fatores presentes desde a sua formação acadêmica até o momento em que foi entrevistada.

O trabalho em um hospital público brasileiro envolve também decisões relativas às condições inadequadas de trabalho (falta de funcionários, de material, de recurso, instalações precárias etc) que interferem na organização do mesmo. Esses fatores têm que, obrigatoriamente, estar presentes durante uma análise qualitativa, pois, do contrário tornam a análise incompleta e não autêntica em relação à realidade. No caso, o habitual acúmulo de tarefas a serem realizadas em curto espaço de tempo é mencionado como motivo para procurar "agilizar" o trabalho, mesmo reduzindo a segurança.

Nesses casos, que envolvem decisões e providências externas ao serviço e mesmo ao hospital (compra de materiais mais adequados, realização de concursos, contratação de pessoal, etc.), a análise qualitativa de casos singulares alimenta uma análise contínua, cruzada com aquela dos dados quantitativos, sustentando as recomendações técnicas que a CST faz ao Hospital. Mas a participação do profissional continua a ser importante, e não apenas como informante: os analistas do trabalho discutem, caso a caso, como a CST e os serviços podem se aliar na pressão pela mudança dos processos de trabalho institucionalizados.

A análise ressalta também o papel do conteúdo do trabalho na construção das referências do ofício. A preocupação com o enfermo e com o procedimento bem realizado tem precedência com relação ao cuidado da profissional consigo mesma. Nesse caso específico, a profissional preocupou-se em executar o procedimento com precisão, mas ao finalizá-lo considerou a tarefa - o atendimento ao paciente - terminada e diminuiu o grau de atenção destinada à mesma. Com isso, descuidou-se do material, que foi colocado na mesa de cabeceira, e sua atenção aos movimentos que ainda teria que executar diminuiu. Em outro momento do diálogo, aparecem justificativas para o reencape de agulhas, relacionadas ao medo que, ficando desencapadas, possam ferir o paciente ou um outro profissional.

Há envolvida na atividade de trabalho, toda uma série de conflitos e a solução para estes requer que se produza uma elaboração de conteúdos, a partir dos próprio recursos subjetivos do trabalhador. Assim, deve-se levar em consideração a tarefa em si, mas também, todo esse arsenal de conflitos vividos pelo trabalhador. No operar de uma determinada tarefa, encontra-se a reunião e o embate de questões técnicas aprendidas ao longo da formação 
acadêmica, de hábitos desenvolvidos durante o tempo de profissão que servem para potencializar e economizar tempo e gestos na realização das atividades, de múltiplos significados atribuídos a cada gesto. São questões que envolvem o relacionamento do trabalhador com seu trabalho (o valor que este possui), com seus colegas e mesmo com questões trazidas de fora do ambiente de trabalho, que permeiam a relação do trabalhador com sua tarefa.

Com a ACAT, coloca-se em aberto a possibilidade de uma formação tanto para o trabalhador, quanto para os analistas do trabalho. Segundo Osorio da Silva (2002), essa análise também recria a prática dos psicólogos do trabalho: esses saem definitivamente do lugar daquele que aconselha para o daquele que compartilha caminhos e soluções.

É através desses encontros com o(s) outro(s) que os indivíduos produzem-se ontologicamente. Toda afecção de forças (homem/objeto, homem/natureza etc.) produz um encontro e deste nada se sabe a priori. O que caracteriza estes encontros é justamente a potência de afetar ambas as partes provocando modificações nestas, que deixam de ser o que eram antes. Sendo assim, a ACAT, como um dispositivo disparador do fazer e falar na situação de trabalho, pode promover uma ampliação do poder de ação dos trabalhadores gerando, concomitantemente, uma produção de subjetividade. No acontecer desses encontros, diversos fluxos presentes no âmbito individual e no coletivo são ativados e os conteúdos presentes, tanto na ação, quanto na reflexão, atravessam-se e tranformam indivíduos e coletivos envolvidos.

A intervenção proposta, via ACAT, tem como meta que esse pontos de estrangulamento possam tornar-se visíveis, tornarem-se objeto de diálogo e negociação, na tentativa de criar uma nova via para os mesmos. Na ACAT não há protagonista incumbido de promover mudanças em determinadas situações - a intervenção entre analistas e acidentado é o motor das modificações e da possibilidade de vencer a descrença acentuada de que os coletivos de trabalho não podem influenciar na organização de seu próprio trabalho.

\section{Referências}

Bálsamo, A. C., Barrientos, D. S. \& Rossi, J. C. B. (2000). Acidentes de trabalho com exposição a líquidos corporais humanos ocorridos nos funcionários do Hospital Universitário da Universidade de São Paulo (HU-USP). Revista Médica HU-USP, 10 (1), 39-45.

Braga, D. (2000). Acidentes de trabalho com material biológico em trabalhadores da equipe de enfermagem do Centro de Pesquisas do Hospital Evandro Chagas. Dissertação de Mestrado, Escola Nacional de Saúde Pública, Fundação Oswaldo Cruz, Rio de Janeiro.

Campos, G. W. de S. (2000). Um método para análise e co-gestão de coletivos. São Paulo: Hucitec.

Center for Disease Control (1989). Guidelines for prevention of transmission of HIV and HBV to healthcare and public-safety workers. Atlanta: US Department of Health and Human Services, Public Health Services.

Chaves, S. et al. (1999). Integrating care and Prevention: Accidental on occupational exposures to blood and body fluids in a general hospital. Montreal: The $4^{\text {th }} \mathrm{ICOH}$ International Conference on Occupational Health for Health Care Workers, WP-17.

Clot, Y. (2000). Genres et styles en analyse du travail. Concepts et méthodes. Travailler: Revue Internationale de Psychopathologie et de Psychodynamique du Travail, 4, 7-42.

Clot, Y. (1999a). La fonction psychologique du travail. Paris: PUF.

Clot, Y. (1999b). Os instrumentos da ação. Les Territoires du Travail, 3, 1999. 
Costa, M. B. \& Schneider, L. O. D. (1998). Condutas nos acidentes de trabalho com materiais biológicos em hospitais. In F. M. de Agosto, R. Peixto \& R. Bordin (Orgs.), Riscos da Prática Médica (pp. 45-65). Porto Alegre: Da Casa Editora.

Lourau, R. (1993). Análise Institucional e Práticas de Pesquisa. Rio de Janeiro: Editora da UERJ.

Machado, J. H. M. (1997). Processo de vigilância em saúde do trabalhador. Cadernos de Saúde Pública, 13 (supl. 2), 33-45.

Minayo-Gomez, C. \& Thedim-Costa, S. M. da F. (1997). A construção do campo da saúde do trabalhador: percurso e dilemas. Cadernos de Saúde Pública, 13 (supl. 2), 21-32.

Oddone, I., Re, A. \& Briante, G. (1981). Redécouvrir l'expérience ouvrière: vers une autre psychologie du travail? Paris: Messidor.

Osorio-da-Silva, C. \& Oliveira, N. (1999). Intervenções em Saúde do Trabalhador - Psicólogos numa Comissão de Saúde do Trabalhador num Hospital Geral Público no Rio de Janeiro. Revista do Departamento de Psicologia - UFF, 11 (1), 40-50.

Osorio-da-Silva, C. (2002). Vida de Hospital: a produção de uma metodologia para o desenvolvimento da saúde do profissional de saúde. Tese de Doutorado, Escola Nacional de Saúde Pública, Fundação Oswaldo Cruz, Rio de Janeiro.

Osorio, C., Machado, J. M. H. \& Minayo-Gomez, C. (2005). Proposição de um método de análise coletiva dos acidentes de trabalho no hospital. Cadernos de Saúde Pública, 21 (2), 517-524.

Passos, E. \& Benevides de Barros, R. (2000). A construção do plano da clínica e o conceito de transdisciplinaridade. Revista Psicologia: Teoria e Pesquisa, 16 (1), 71-79.

Endereços para correspondência:

camilaaalves@hotmail.com, claudiaosorio@terra.com.br

Recebido em: 15/12/2004

Envio de pareceres em: 17/03/2005

Aprovado em: 14/06/2005 